\title{
An evaluation of male learners' knowledge, attitudes and practices regarding sexual and reproductive health in rural northern KwaZulu-Natal province
}

\author{
Mampho Mochaoa Rogers ${ }^{\mathrm{a}, \mathrm{b} *} \mathbb{1}^{\mathrm{C}}$, Gloria Mfeka-Nkabinde ${ }^{\mathrm{b}}$ and Andrew Ross ${ }^{\mathrm{b}}$ \\ ${ }^{a}$ Bethesda Hospital, Department of Health, Ubombo, South Africa \\ ${ }^{b}$ Discipline of Family Medicine, School of Nursing and Public Health, College of Health Sciences, University of KwaZulu-Natal, \\ Durban, South Africa \\ *Corresponding author, email: mamphomr@gmail.com

Background: With a disparate HIV prevalence among young men and women, high rates of teenage pregnancies and a lack of responsible fatherhood, issues of reproductive health among young people need to be urgently addressed. The aim of this research was to assess the knowledge, attitudes and practices regarding sexual and reproductive health among young men in the Bethesda Hospital catchment area of northern KwaZulu-Natal province.

Methods: This observational, descriptive cross-sectional study was conducted at six randomly selected high schools within the uMkhanyakude district. All grade 12 male learners $\geq 18$ years completed a questionnaire regarding their reproductive health knowledge, attitudes and practices.

Results: A total of 279 learners participated in the study with a median age of 20.2 years and a mean knowledge score of $63.8 \%$. Only $28.3 \%$ of the learners showed good or excellent knowledge on basic sexual and reproductive health questions; $50.9 \%$ believed that girls say 'no' to sex when they mean 'yes', and $46.2 \%$ believed that girls were sexually aroused when dominated by a man. Some 156 (55.9\%) of those who were sexually active did not know their current sexual partner's HIV status. There were significant associations between being brought up in a female-headed family and early sexual debut but not between early sexual debut and paternalistic attitudes to women.

Discussion and conclusions: Basic sexual and reproductive health knowledge among the majority of participants was adequate. Patriarchal attitudes of sexual domination were prominent, and these are probably influenced by sociocultural belief systems of traditional masculinity, which are defined and dominated by men. This perpetuates gender inequality and contributes to poor sexual and reproductive health outcomes. Poor health-seeking behaviour and attitude relating to sexually transmitted infections (STIs), and having concurrent multiple sexual partners, puts them and their sexual partners at risk of HIV/AIDS acquisition. Strategies need to be developed to enhance socially acceptable and comprehensive sexual and reproductive health education and services among young men in this area, foster positive attitudes towards women and encourage gender-equal relationships.

Keywords: attitude, behaviour, knowledge, rural setting, sexual and reproductive health, young male learners

\section{Background}

Young people aged $10-24$ years account for $25 \%$ (1.8 billion) of the world's population, ${ }^{1}$ with $88 \%$ of the adolescent ${ }^{2}$ population (adolescent: 10-19 years) residing in developing countries, of whom one in five live in sub-Saharan Africa (SSA). ${ }^{2}$ Such a large adolescent population presents an opportunity for economic development, and is the foundation for remodelling the future of many African countries. ${ }^{3}$ However, the social and economic trajectory of such development requires healthy citizens who can maximise their potential and actively participate in such job and economic opportunities. Within this context, issues of sexual and reproductive health can impact negatively on African youth, including those in South Africa (SA). ${ }^{4}$ Studies have indicated that at least $50 \%$ of teenagers in SA are sexually active by 16 years of age ${ }^{5}$ this being of concern in a country with HIV prevalence rates of up to $39.4 \%$ among young women and $15 \%$ among young men. ${ }^{6}$ The high rates of teenage and unwanted pregnancies, ${ }^{1}$ and a lack of responsible fatherhood, highlight the need to address issues regarding their reproductive health. While human reproduction is often perceived as the woman's responsibility, ${ }^{7}$ it needs to be a dual commitment, with its outcome being a shared responsibility. ${ }^{8}$ According to the United Nations, reproductive health and well-being should encompass the following: all pregnancies should be intended, all births should be healthy and sexual activity should be free of coercion or violence and infection. ${ }^{9,10}$

Young women are at a higher risk for HIV acquisition than men due to a complex combination of biological, behavioural, structural and sociocultural factors that have resulted in high rates of new infections. ${ }^{11,12}$ Due to the disproportionately high prevalence of HIV in young women, research has focused on this population, often to the exclusion of young men. The literature is replete with interventional studies that target young women in SSA as key role players to transform and improve sexual and reproductive health outcomes. ${ }^{8,13}$ However, despite the poor health outcomes related to unwanted pregnancies and HIV/AIDS, many interventional studies that seek to address these problems continue to focus solely on young women in isolation from young men as an integral part of the solution. ${ }^{13,14}$ Very little interventional research has focused on the role of young men in the sexual and reproductive health outcomes in SSA, with some evidence suggesting that their attitudes towards sex, females and relationships in general are often associated with negative health and social consequences. ${ }^{13,15,16}$

The uMkhanyakude District has the highest in-facility delivery rate for girls under 18 years of age in KwaZulu-Natal province, which at $10.7 \%$ is the third highest in SA. ${ }^{17}$ This rural district is 
one of the most impoverished in SA, and is characterised by low levels of education, a high unemployment rate and a high burden of HIV infection. ${ }^{18}$ At Bethesda Hospital, a rural district hospital in the Jozini Municipality of uMkhanyakude District, the 2015/16 perinatal statistics showed that there were 2075 deliveries at the hospital, of which $11.1 \%$ (231) were to women below 18 years of age. ${ }^{19}$ South African literature demonstrates that a low proportion of adolescent mothers have children with males of a similar age; ${ }^{20}$ however, this is different in KwaZulu-Natal Province, which has the highest percentage of young men fathering children born to adolescent mothers. ${ }^{20}$ This trend indicates the need to better understand young men's views on sexual and reproductive health issues and responsible fatherhood. The aim of this research was to assess the knowledge, attitudes and practices of young men in the Bethesda Hospital catchment area regarding their sexual and reproductive health, and to make recommendations for future interventions.

\section{Methods}

Bethesda hospital is a 220-bed district hospital situated in the village of uBombo, in the Jozini Municipality of the uMkhanyakude District in northern KwaZulu-Natal province. The hospital is responsible for providing care to a large geographical area with a mainly rural African population of approximately 101910 people. $^{18}$ This population is traditionally a patriarchal society, with $89 \%$ of the people living on land under the leadership of traditional authorities (amakhosi). ${ }^{21}$ Employment in the formal sector is limited, with many homes relying on subsistence agriculture, social grants and income from absent household members.

There are 20 high schools in the Bethesda catchment area, and according to Stats SA, 81\% of those aged between 5 and 24 years attend school. ${ }^{21}$ In 2017, the school's attendance register recorded 883 Grade 12 male learners aged 18 years and above at these high schools. Using the Epi Info statistical calculator (CDC, Atlanta, GA, USA), input from a biostatistician, and based on a confidence interval of $95 \%$ and a margin of error $5 \%$, a minimum sample size of 258 high school male learners aged $\geq 18$ years was determined. ${ }^{22}$ To obtain the study's minimum sample size, 6 high schools out of the 20 were randomly selected to be included in the study. Based on figures from the Department of Education, there were 353 Grade 12 male learners aged $\geq 18$ years at these six high schools, which exceeded the minimum required sample size. Within each selected school, all Grade 12 male learners 18 years and above who met the inclusion criteria and consented to participate were included in the study.

The knowledge, attitudes and practices of these young men were assessed to establish whether they had accurate knowledge, and to what extent this informed their attitudes and practices. The survey instrument was a pretested, self-administered and semi-structured questionnaire consisting of 5 demographic variables and 49 study-specific questions developed from standardised sexual assessment scores that had been used in similar studies elsewhere in the world. ${ }^{23}$ The 13 knowledge questions assessed knowledge regarding HIV/STI acquisition, treatment and prevention, male medical circumcision (MMC), risk factors and complications associated with teenage pregnancy, knowledge of the female reproductive system, and the menstrual cycle. Eighteen questions focused on attitudes towards shared responsibilities on sexual decisions and sexual acts, intimate partner violence, abortion, fatherhood, prevention of unwanted or unplanned pregnancies, as well as their views on gender inequality and masculinity. A further 18 questions focused on sexual practices, and included age of sexual debut, male medical circumcision (MMC), the use of contraception/ condom in preventing unwanted pregnancies, preventing HIV and other STIS, HIV testing and the number of recent sexual partners. Knowledge responses were aggregated and evaluated, and those who scored $>80 \%$ correct were considered to have excellent knowledge, $60-79 \%$ correct were regarded as having good knowledge, those with $51-59 \%$ had some knowledge and those who scored $<50 \%$ correct were considered to have poor knowledge.

The questionnaire was translated from English to isiZulu, the local language, and back-translated to ensure that the questions were clear and unambiguous. A pilot study consisted of 10 young men who met the inclusion criteria from a high school in the study area that had not been included in the study, and this resulted in minor modifications being made to the questionnaire. Between March and April 2018, the researcher and two research assistants visited all six schools and arranged to meet with all the students who met the inclusion criteria to administer the questionnaire. The questionnaire was administered only once at each school, and the students who were absent on the day did not participate in the study. It was available in English and isiZulu, with the students being able to decide on the language of their choice. All questionnaires were completed anonymously, with no identifying characteristics being indicated. The data were captured and analysed using intercooled Stata version 13 (StataCorp, College Station, TX, USA) for nonparametric tests and SPSS version 18. SPSS Inc, Chicago, IL, USA for parametric tests. Descriptive statistics, such as number and percentages, were used to summarise the categorical data. Measure of central tendency such as mean and median, and measures of dispersion, such as standard deviation, were calculated from the numerical variables. Permission to conduct the research was obtained from the Department of Basic Education and Principals at each of the six schools, and all participants signed informed consent before completing the questionnaire. Ethical approval was obtained from the University of KwaZulu-Natal's Biomedical Research Ethics Committee (BE 309/17).

\section{Results}

The participants' demographic details are illustrated below, followed by their knowledge, attitudes and practices relating to their sexual behaviour.

\section{Demographic details}

Of the 353 questionnaires distributed, 279 were returned, of which all were from young black men, giving a $79 \%$ response rate, which was 10 more than the minimum required number for statistical analysis. The 279 study participants had a mean age of 20.27 years ( $S D=1.9$ years) with $43 \%$ being 18 and 19 years old, and the oldest being 26 years (range 18-26 years) (Figure 1).

Other sociodemographic responses are presented in Table 1, with $36.2 \%(100 / 276)$ and $19.2 \%(53 / 276)$ being raised by single mothers or grandparents respectively. The majority of participants $(88.2 \%$; 224/254) came from households where their parents or guardians were either employed or had a casual job and received some form of social grant, while $11.8 \%(30 / 254)$ of households had no formal source of income and did not receive a social grant. 


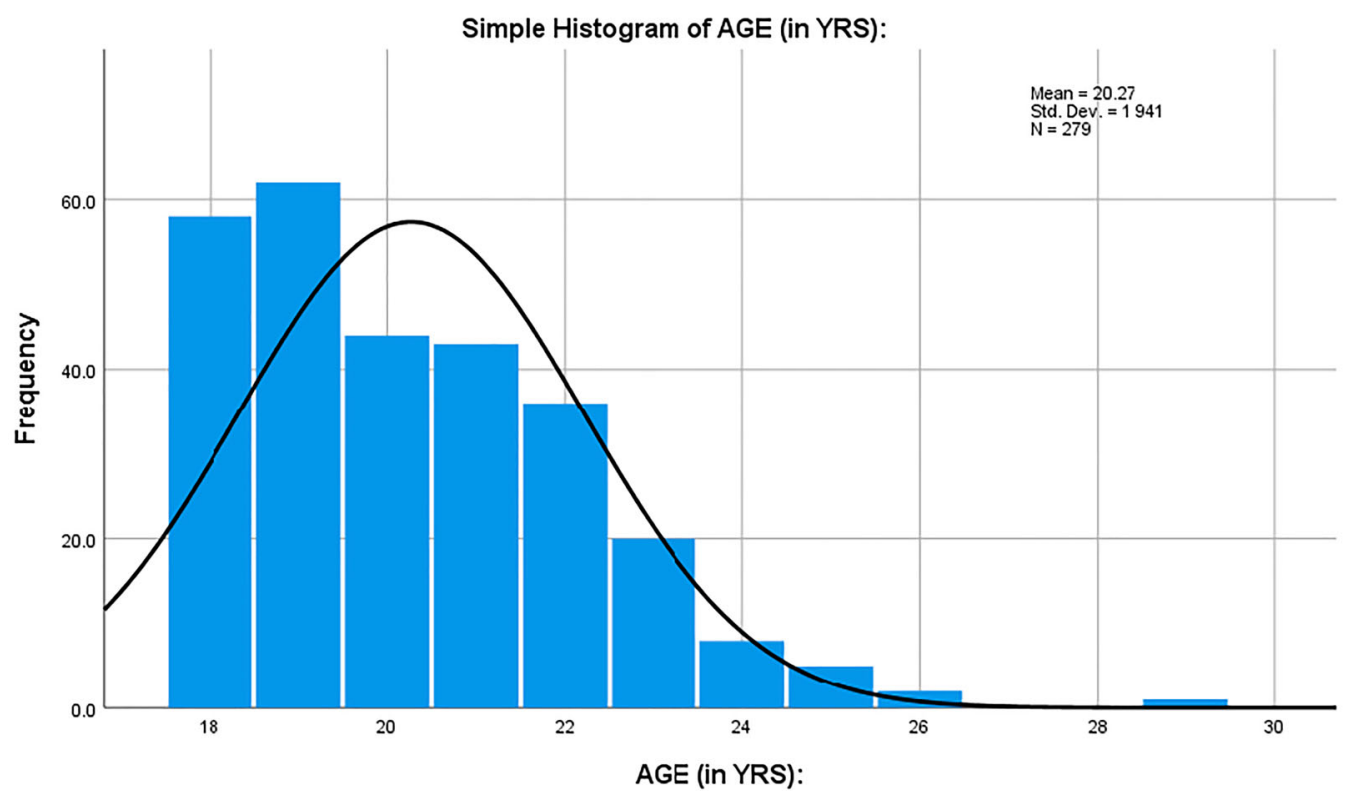

Figure 1. Age distribution of young males attending selected Bethesda Hospital catchment area schools, $2018(n=279)$.

\section{Sexual and reproductive health knowledge}

Of the 279 young men, only 23 (8.2\%) had excellent knowledge, $56(20,1 \%)$ had good knowledge, $92(33 \%)$ had some knowledge while $108(38.7 \%)$ had poor knowledge. There were, however, important gaps in knowledge with $84.2 \%$ (235) stating that a woman can fall pregnant anytime during her menstrual cycle and 127 (45.5\%) indicating that a woman can fall pregnant while menstruating - see Table 2 . Knowledge regarding the negative consequences associated with teenage pregnancy is an important indicator of one's understanding of sexual and reproductive health-related outcomes. A substantial number of participants had poor knowledge of emotional development related to sexual practices as $168(60.2 \%)$ stated that such babies have few problems because their parents are emotionally mature. Of the 279 participants, most knew their HIV status, with $182(65.2 \%)$ reporting to be HIV-negative, two (0.7\%) being HIVpositive, and 95 (34.2\%) reporting not having been tested.

While the majority of participants knew that condoms help prevent HIV and other STIs, 99 (36\%) thought that condoms have dangerous side effects. Most $(86 \% ; 240)$ knew that condoms were readily available and could be bought in a supermarket without a prescription. Regarding the management of a penile discharge, $81.4 \%$ thought that it would resolve

Table 1: Participants' reproductive health knowledge scores in relation to demographic details

\begin{tabular}{|c|c|c|c|c|c|c|}
\hline \multirow[b]{2}{*}{ Variables } & & \multicolumn{4}{|c|}{ Frequency within knowledge score range } & \multirow[b]{2}{*}{ Total } \\
\hline & & $\begin{array}{c}>80 \% \\
\text { (Excellent) }\end{array}$ & $\begin{array}{c}60-79 \% \\
\text { (Good) }\end{array}$ & $\begin{array}{c}50-59 \% \\
\text { (Some) }\end{array}$ & $\begin{array}{l}<50 \% \\
\text { (Poor) }\end{array}$ & \\
\hline \multirow[t]{3}{*}{ Age } & $18-20$ & 17 & 38 & 44 & 65 & $164(58.8)$ \\
\hline & $21-23$ & 6 & 18 & 43 & 32 & $99(35.5)$ \\
\hline & $24-26$ & 0 & 0 & 5 & 11 & $16(5.72)$ \\
\hline \multirow[t]{5}{*}{ Parent/ Guardian** } & Father and mother & 3 & 16 & 32 & 28 & $79(28.6)$ \\
\hline & Father only & 1 & 2 & 3 & 3 & $9(3.3)$ \\
\hline & Mother only & 14 & 18 & 28 & 40 & $100(36.2)$ \\
\hline & Grandparents & 5 & 11 & 13 & 24 & $53(19.2)$ \\
\hline & $\begin{array}{l}\text { Other: }{ }^{*} \mathrm{CHH}^{\mathrm{a}} \text {, foster parents or } \\
\text { other relatives }\end{array}$ & 0 & 6 & 16 & 13 & $35(11.6)$ \\
\hline \multirow[t]{2}{*}{ Tested for HIV } & Yes & 18 & 44 & 60 & 60 & $182(65.2)$ \\
\hline & No & 5 & 12 & 30 & 48 & $95(34.0)$ \\
\hline \multirow{6}{*}{$\begin{array}{l}\text { Source of household } \\
\text { income** }\end{array}$} & Formal employment & 7 & 28 & 30 & 15 & $80(31.5)$ \\
\hline & Self-employed & 9 & 5 & 10 & 10 & $34(13.4)$ \\
\hline & Casual jobs and social grant & 4 & 6 & 8 & 11 & $29(11.4)$ \\
\hline & Casual jobs and no social grant & 0 & 1 & 6 & 8 & $15(5.9)$ \\
\hline & Unemployed and on social grant & 0 & 10 & 26 & 50 & $86(33.8)$ \\
\hline & Unemployed and no grant & 1 & 6 & 9 & 14 & $30(11.8)$ \\
\hline
\end{tabular}

\footnotetext{
a ${ }^{*} \mathrm{CHH}=$ child headed household; ${ }^{* *}$ some data missing; not everyone answered this question.
} 
Table 2: Knowledge responses on different aspects of sexual and reproductive health

\begin{tabular}{|c|c|c|}
\hline \multirow[b]{2}{*}{ Statement } & \multicolumn{2}{|c|}{ Frequency of response } \\
\hline & Yes & No \\
\hline \multirow{4}{*}{$\begin{array}{l}\text { 1. A girl can fall pregnant: } \\
\text { - any time of the month } \\
\text { - one week before her periods } \\
\text { - while menstruating }\end{array}$} & $235(84.2 \%)$ & $44(15 \%)$ \\
\hline & $197(70.6 \%)$ & $82(29.4 \%)$ \\
\hline & $127(45.5 \%)$ & $152(54.4 \%)$ \\
\hline & & \\
\hline \multirow{3}{*}{$\begin{array}{l}\text { 2. Babies born to teenage mothers: } \\
\text { - have a higher chance of not being offered breastfeeding } \\
\text { - have few problems because their parents are emotionally mature }\end{array}$} & 192 (69\%) & $86(31 \%)$ \\
\hline & 110 (39.4\%) & $168(60.2 \%)$ \\
\hline & & \\
\hline \multirow{3}{*}{$\begin{array}{l}\text { 3. Condoms: } \\
\text { - help prevent getting HIV and other STIs } \\
\text { - do not have dangerous side effects }\end{array}$} & 276 (98.9\%) & $3(1.1 \%)$ \\
\hline & 99 (36\%) & $179(64.2 \%)$ \\
\hline & & \\
\hline \multirow{3}{*}{$\begin{array}{l}\text { 4. Syphilis } \\
\text { - is one of the dangerous sexual diseases } \\
\text { - causes blindness, mental disorder and death if not treated }\end{array}$} & $230(82.4 \%)$ & $49(17.6 \%)$ \\
\hline & $60(21.5 \%)$ & 219 (78.5\%) \\
\hline & & \\
\hline \multirow{3}{*}{$\begin{array}{l}\text { 5. Children of teenage parents usually: } \\
\text { - are at a greater risk of being abused by their parents } \\
\text { - weigh a normal weight at birth as per their gestational age }\end{array}$} & $245(87.8 \%)$ & $34(12.2 \%)$ \\
\hline & $48(17.2 \%)$ & $231(82.8 \%)$ \\
\hline & & \\
\hline \multirow{3}{*}{$\begin{array}{l}\text { 6. Penile discharge: } \\
\text { - is caused by inflammation of the urethra and is usually related to STDs } \\
\text { - does not require any action as it will disappear }\end{array}$} & $67(24 \%)$ & 212 (76\%) \\
\hline & 227 (81.4\%) & $52(18.6 \%)$ \\
\hline & & \\
\hline
\end{tabular}

Table 3: Participants' attitudes towards women and sex

\begin{tabular}{|c|c|c|c|}
\hline Statement & Agree, $\mathrm{n}(\%)$ & Neutral, n (\%) & Disagree, $\mathrm{n}(\%)$ \\
\hline 1. By being dominated, girls get sexually aroused & $129(46.2)$ & $136(48.8)$ & $14(5.0)$ \\
\hline 2. A man's masculinity should be proven in sexual situations & $111(39.8)$ & $76(23.2)$ & $92(33.0)$ \\
\hline 4. It is a girl's right to refuse sex any time & $224(80.4)$ & $32(11.4)$ & $23(8.2)$ \\
\hline 5. Even if a man wants sex, he shouldn't if the girl's consent is not granted & $204(73.1)$ & $36(13.1)$ & $39(14.0)$ \\
\hline $\begin{array}{l}\text { 6. Every time I engage in sexual activity, it is also my responsibility to } \\
\text { ensure that I don't cause unwanted pregnancy or transmit HIV/STIs }\end{array}$ & $222(79.6)$ & 29 (10.4) & $28(10.0)$ \\
\hline 7. Men should be involved in antenatal and postnatal care & $238(85.3)$ & $34(12.2)$ & $7(2.5)$ \\
\hline
\end{tabular}

spontaneously and only $18.6 \%$ knew that medical treatment was necessary.

\section{Attitude}

Only $5 \%$ (14) disagreed that women get sexually aroused when being dominated, while over 50\% (142) believed that girls say 'no' to sex when they mean 'yes', and $80 \%$ felt that women have a right to refuse to have sex (Table 3 ). The majority (238; $85.3 \%$ ), believed that men should be involved in antenatal and postnatal care should their sexual partner fall pregnant. Furthermore, the majority $(236 ; 84.6 \%)$ agreed that parenting is the responsibility of both the mother and the father. With regard to abortion, the majority $(96.4 \% ; 269)$ said they would not advise their girlfriend to abort their baby but would rather ask their mother or grandmother to care for the child.

\section{Practice}

Table 4 presents information on sexual debut with 95 (34.1\%) starting sexual activity between the ages of 15 and 17 years, and 238 (85.3\%) reporting being sexual active, of whom 40 (14.3\%) had at least one child.

In total, 120 participants (43\%) reported having had only one sexual partner in the last 6 months while 107 (38.4\%) reported having had more than one sexual partner in the last 6 months and $50(17.9 \%)$ reported not having been sexually active in the last 6 months. In terms of safer sexual practices, only 84 (30.1\%) had a single-partner relationship and used condoms, while 161 (87.9\%) used the condom only. Furthermore, 20 (7.2\%) said they engaged in single-partner relationships only as a form of practising safer sex. Just over two-thirds (182; $65.3 \%)$ were circumcised, with $160(57.3 \%)$ indicating that they had this done to prevent HIV transmission. More than half (156; 55.9\%) of those who were sexually active did not know their current sexual partner's HIV status.

There was no significant relationship between sexual and reproductive health knowledge and age at sexual debut, (chi-square

Table 4: Participants' sexual practices

\begin{tabular}{lcc}
\hline Age at sexual debut (years) & $\boldsymbol{n}$ & $\%$ \\
\hline$<12$ & 19 & 6.8 \\
$12-14$ & 12 & 4.3 \\
$15-17$ & 95 & 34.1 \\
$>17$ & 112 & 40.1 \\
Still a virgin & 37 & 13.3 \\
Missing & 4 & 1.4 \\
Total & 279 & 100 \\
\hline
\end{tabular}


$[12, n=279]=26.004, p=0.114)$, nor between knowledge scores and the number of sexual partners in the last 6 months (chisquare $[3, n=279]=7.348, p=0.53$ ). However, there was a significant association between being brought up in a femaleheaded family and sexual debut under 18 years of age sexual debut (chi-square $[2, n=279]=34.2865, p=0.05$ ), with boys raised in these families more likely to engage in earlier sexual practices and an association between age of sexual debut and patriarchal attitudes that masculinity should be proven in sexual acts. There was not a statistically significant association between age of sexual debut and 'men's masculinity should be proven in sexual situations' ( $p=0.536)$, but there was a statistically significant difference among those who were circumcised versus not circumcised $(p=0.034)$ and their age of sexual debut.

\section{Discussion}

South Africa has a youthful (14-35 years of age) population, ${ }^{24}$ with young people comprising $36.2 \%$ of the total South African population of 55.6 million people. ${ }^{18}$ The majority of these young people reside in rural areas. It is therefore essential that their health issues are addressed, as they face numerous health challenges, including HIV and other STIs, teenage pregnancy, absent fathers, poverty and gender-based violence. ${ }^{1}$

The demographic details of the young men who participated in this study indicate that mothers and grandparents were responsible for the upbringing of $54.8 \%$ (153/279) of the participants. This is in keeping with other studies that have reported rural women (mothers and grandmothers) as often carrying the responsibility of bringing up children in fragile family structures. ${ }^{25}$ The negative impact of absent fathers has been shown to have significant detrimental effects on the well-being of children and young people. ${ }^{26,27}$ Absent fathers and family breakdown negatively impact on education, youth development, teenage pregnancy, youth attitudes to sex and HIV/AIDS, youth violence, crime and mental health. ${ }^{26,27}$ The findings of this study are consistent with other studies demonstrating that adolescents raised in a household with an absent father are more likely to engage in early sexual debut, ${ }^{6}$ which has been shown to almost triple the risk of adolescent pregnancy. ${ }^{20,28}$ In addition, young people living in poverty ( $41 \%$ of participants in this study are from families dependent on social grants) and with few prospects in life are also more likely to have unplanned pregnancies. $^{25}$

Although the majority of participants had adequate knowledge about the female reproductive system, most had a poor understanding of the menstrual cycle and when a woman can fall pregnant, which is of concern. Despite having to participate in compulsory life orientation classes in school, which include reproductive health, ${ }^{29}$ basic reproductive knowledge appeared to be lacking in many of the participants. Their poor understanding of a woman's menstrual cycle and the window in which she can fall pregnant casts doubt on shared decision-making regarding contraception use. Participants also had poor knowledge of STIs and the need for medical treatment for both partners, even if the symptoms improved. This lack of basic understanding of the management of STIs has been reported to be a major risk factor in the transmission of HIV. ${ }^{30}$ These findings are consistent with other studies that have reported poor reproductive health knowledge among the young in rural areas of SA. ${ }^{30,31}$ They also point to a need for monitoring and evaluation of the School Health Services as one of the strategic objectives of the Integrated School Health Policy (ISHP) is to provide health prevention and health promotion services, which address health needs of scholars and youth. ${ }^{29}$ This policy is in line with the WHO recommendations on school health services provision and requires ongoing efforts in its implementation and evaluation across all schools in the country, particularly rural schools located in resource-constrained settings.

Only $65 \%$ of participants who were sexually active knew their HIV status, which is considerably lower than the 90-90-90 UNAIDS initiative to ensure that $90 \%$ of the population know their HIV status. ${ }^{32}$ A recent study by Ntombela et al. has reported on research outcomes which suggest that being black African male, having low levels of education, being from a rural area and being unemployed are all associated with lower knowledge of one's own HIV status, ${ }^{33}$ and increase HIV risk behaviours in men. ${ }^{34}$ It was of concern that just over a third of those who were sexually active were knowledgeable about their partner's HIV status. This highlights the challenges of engaging in discussions between young men and women on sexual issues and on negotiating safe sexual practices. Only two participants $(2 / 279$; $0.007 \%$ ) indicated that they were HIV-positive, which is much lower than the national HIV prevalence rate of $14.8 \%$ for males in the 15-49-year-old age range, ${ }^{6}$ and lower than the prevalence rate of $29.4 \%$ in the uMkhanyakude District. ${ }^{35}$ This was an unexpected finding but not difficult to understand, as participants may have found it difficult to disclose this information, despite the confidential nature of the questionnaire.

The young men's patriarchal attitude towards women and its association with early sexual debut and multiple sexual partners paint a rather concerning picture. Almost half of the participants $(46 \%, 129)$ believed that girls are sexually aroused when being dominated by a man, and that girls say 'no' to sex when they actually mean 'yes'. These attitudes exist within the backdrop of rurality, with sociocultural structures that are defined and dominated by men and prop up traditional masculinity. This perpetuates gender imbalances and contributes to poor reproductive health outcomes. ${ }^{15,36}$ The WHO consensus on the definition of reproductive health emphasises that all sexual activity should be free of coercion. ${ }^{9,10}$ The study participants indicated some ambivalence towards young women's ability to have control of their own sexual decisions. Despite over $50 \%$ of the participants suggesting that 'no' might mean 'yes' to sex, the majority $73.1 \%$ (204) agreed that women should not be forced to have sex, while $13.1 \%$ (36) were neutral and $14 \%$ (39) disagreed. This ambivalence needs to be further explored and may provide an opportunity for discussions on sexual and power relations between men and women. This is particularly important as South Africa is known to have one of the highest levels of gender-based violence in the world, ${ }^{20}$ with up to $15 \%$ of learners being forced to have sex and half of adolescents in romantic relationships reporting gender-based violence. ${ }^{37}$ There is evidence suggesting that gender inequality, together with genderbased violence, is a significant obstacle to better sexual and reproductive health outcomes. ${ }^{9}$ In addition, gender inequality has been shown to affect the ability of women and girls to protect themselves from HIV anda unwanted pregnancies, and to access and continue to use HIV prevention, care and treatment services. ${ }^{16}$ This unequal balance of social power between (young) men and women in Africa, together with the patterns of risky behaviours among young men, suggests that they play a central role in shaping the future of the HIV epidemic. ${ }^{15}$

The overall attitude towards parenting was a positive one, with male participation in antenatal care and child-bearing decisions being shown to be to have a positive impact on the acceptability 
of prevention of mother to child transmission (PMTCT) interventions. ${ }^{38}$ Providing suitable high-quality medical education to men has been shown to have important consequences related to PMTCT interventions. Well informed men are more likely to participate positively in decision-making for the well-being of the couple, ${ }^{38,39}$ including making decisions together relating to the choice of contraceptive method, and encouraging and supporting breastfeeding practices for the newborn. However, current practices at hospitals and clinics often militate against the involvement of the sexual partner in these decisions. Antenatal HIV counselling and testing (HCT) usually provides services for women alone, with the assumption that they will disclose results to their partner. However, it has been found that most pregnant women, including those in stable relationships who are tested as part of routine care, do not inform their partners of their positive results, fearing domestic violence, abandonment or stigmatisation. ${ }^{40-42}$

The overwhelming majority of respondents said they would not advise their girlfriend to have an abortion should she fall pregnant while still at school, and would not advise her to give up the baby for adoption either, but to have their family care for it. These findings are in keeping with other studies where rural young men did not want their baby aborted and would like to be involved in the decision about whether or not the woman should terminate the pregnancy. ${ }^{43}$ Despite $79.6 \%$ (222) agreeing that they should take 'shared responsibility' for sexual acts in using contraception to prevent unwanted pregnancies and the spread of HIV, it was not clear how this was to be negotiated.

Regarding their sexual health practices, $87 \%$ of the young men were sexually active, with $38.4 \%$ (107) reporting their sexual debut between 12 and 17 years of age, which is consistent with the Reproductive Health and HIV Research Unit (RHRU) 2003 survey. $^{7}$ Of the $57 \%$ (161) who said they may use condoms when engaging in sexual activity, very few $(84 ; 30 \%)$ elected to use both single-partner relationship and condoms as means of practising safe sex. Slightly more than one-third $(107,38.4 \%)$ reported having had more than one sexual partner in the past six months, which is consistent with other studies. $^{12}$ Research has indicated that young men have a higher number of concurrent and overall sexual partners than young women. This phenomenon, together with inconsistent condom use, places both the young men and their female partners at a much higher risk of contracting HIV and other STIs, as unprotected sex with multiple sexual partners is known to escalate the risk of HIV acquisition. ${ }^{36}$ While most participants were aware of where they could access condoms, 35\% believed that condoms could have serious side effects, despite the majority claiming that they would use them to practise safe sex. The conflicting results of knowing the positive benefits of using condoms yet having misconceptions about their safety also needs addressing. This, together with the practice of having multiple sexual partners and poor health-seeking behaviour regarding STI management, will continue to impact negatively on the sexual and reproductive well-being of young people if not properly addressed.

Just over two-thirds (65\%) of the participants reported being circumcised, which is not a cultural practice among Zulu men since it was banned by King uShaka in the early $1800 \mathrm{~s} .{ }^{44}$ It is encouraging that the majority of participants indicated that they had been circumcised for the prevention of HIV transmission, suggesting that the HIV prevention messages are gaining momentum. Evidence from the study on MMC in Orange Farm in SA concluded that safe circumcision can offer at least $60 \%$ protection from HIV infections among males, and should be part of routine healthcare promotion before young men become sexually active. ${ }^{42}$ The government target for MMC among men is to have over $80 \%$ of men circumcised, suggesting that more needs to be done among the young men in the Bethesda catchment area in order to achieve this.

\section{Study limitations}

The limitations to this study include the exclusion of male students in other grades who were $\geq 18$ years of age, and the assumption that those still at school were representative of young men in the general population, including those no longer at school. However, the uMkhanyakude District is a homogeneous rural area, with the sampling method ensuring that all communities falling under the Bethesda catchment area were represented, suggesting that the study outcomes can be generalisable to the entire sub-district and other similar rural settings.

\section{Conclusion and recommendations}

The study findings highlight several concerning issues regarding young men's knowledge, attitudes and practices regarding sexual and reproductive health in the Bethesda Hospital catchment area. They perhaps also point to major deficiencies or challenges in the implementation, evaluation and monitoring of the life orientation programme, and the important role that the school health team could play in comprehensive sexual and reproductive health education. As part of the primary health care $(\mathrm{PHC})$ re-engineering initiative, there is only one school health team in the Bethesda catchment area that visits each of the 44 primary and 20 high schools over the course of the year. At primary schools, the school health team focuses on immunisation and deworming, while at high schools they focus on the sexual and reproductive health issues, including menstruation and contraception, MMC, STIs, HIV/AIDS and teenage pregnancy. ${ }^{29}$ However, despite their visits and healthpromotion talks at local high school assemblies, major gaps remain in basic reproductive knowledge among the majority of young men who participated in the study. This study highlights the need for focused sexual and reproductive health education and services for young men, and strategies to foster positive attitudes towards women and gender equitable norms. There is an ideal opportunity for a comprehensive and socially acceptable follow-up community-orientated interventional study in this area to enhance their sexual and reproductive health knowledge, encourage positive attitudes towards women, and to improve the sexual and reproductive health outcomes in uMkhanyakude district. This would require multisectoral collaboration between the Department of Health, Basic Education, Social Development, traditional leadership, parents, school governing bodies and NGOs.

Acknowledgements - The first author would like to acknowledge the help and support of his supervisors Dr N.G. Mfeka-Nkabinde and Professor A. Ross. In addition, thanks are offered to the Discovery Foundation Fund, the research assistants and all the young men of UMkhanyakude who participated in this study.

Disclosure statement - No potential conflict of interest was reported by the authors. 


\section{ORCID}

Mampho Mochaoa Rogers (1) http://orcid.org/0000-0002-40964934

\section{References}

1. Edwards $\mathrm{O}$, Peterson $\mathrm{N}$. The sexual and reproductive health of young people in low and middle income countries 2013. Available from: https://advocatesforyouth.org/wp-content/uploads/storage//advfy/ documents/our-moment-girls-fs1.pdf.

2. WHO. Maternal, Newborn, Child and Adolescent data. https://www. who.int/data/maternal-newborn-child-adolescent/adolescent-data. Geneva, Switzerland. 2017. Accessed: 27/09/2019.

3. Savage-Oyekunle OA, Nienaber A. Adolescent girls' access to contraceptive information and services: an analysis of legislation and policies, and their realisation, in Nigeria and South Africa. Afr Hum Rts L J. 2015;15(2):433-48.

4. Hindin MJ, Fatusi AO. Adolescent sexual and reproductive health in developing countries: an overview of trends and interventions. Int Perspect Sex Reprod Health. 2009;35(2):58-62.

5. Eaton L, Flisher AJ, Aaro LE. Unsafe sexual behaviour in SA youth. Soc Sci Med. 2003;56:149-65.

6. (HSRC) HSRC. The 5th South African National HIV PrevalenceSABSSMV 2018 [updated July 2018. Available from: http://www. hsrc.ac.za/uploads/pageContent/9234/SABSSMV_Impact Assessment_Summary_ZA_ADS_cleared_PDFA4.pdf.

7. Cook RJ, Dickens BM, Fathalla MF. Reproductive health and human rights: integrating medicine, ethics, and law. Reproductive and sexual health. Oxford, United Kingdom. Oxford scholarship online: Clarendon Press; 2003. p. 14-5.

8. Mbizvo MT, Bassett MT. Reproductive health and AIDS prevention in sub-Saharan Africa: the case for increased male participation. Health Policy Plan. 1996;11(1):84-92.

9. Bloom SS, Tsui AO, Plotkin M, Bassett $S$. What husbands in northern India know about reproductive health: correlates of knowledge about pregnancy and maternal and sexual health. J Biosoc Sci. 2000;32(2):237-51.

10. Cohen SA, Richards CL. The Cairo consensus: population, development and women. Fam Plann Perspect. 1994;26(6):272-7.

11. Pettifor $A E$, Rees HV, Kleinschmidt I, Steffenson AE, MacPhail C, Hlongwa-Madikizela $L$, et al. Young people's sexual health in South Africa: HIV prevalence and sexual behaviors from a nationally representative household survey. AIDS. 2005;19(14):1525-34.

12. Shisana O, Rehle T, Simbayi L, Zuma K, Jooste S, Zungu N, et al. South African national HIV prevalence, incidence and behaviour survey, 2012. 2014.

13. Sternberg P, Hubley J. Evaluating men's involvement as a strategy in sexual and reproductive health promotion. Health Promot Int. 2004;19(3):389-96.

14. Fransen-dos Santos R. Young people, sexual and reproductive health and HIV. Bull World Health Organ. 2009;87(11):877-9.

15. Barker G, Ricardo C. Young men and the construction of masculinity in sub-Saharan Africa: implications for HIV/AIDS, conflict, and violence. Washington, DC: World Bank; 2005.

16. Ghanotakis E, Peacock D, Wilcher R. The importance of addressing gender inequality in efforts to end vertical transmission of HIV. J Int AIDS Soc. 2012;15(4):1-11.

17. Massyn NPA, Peer N, Day C. District Health Barometer 2016/2017. 2017 2016/2017. Report No.: 978-1-919839-92-9.

18. Statistics South Africa, 2016. In: Africa SS, editor. Soth Africa, Pretoria: Stats SA Library Cataloguing-in-Publication (CIP) Data; 2016.

19. Massyn NPA, Peer N, Day C. District Health Barometer 2015.

20. Mkhwanazi S. Teenage pregnancy in South Africa: setting the new research agenda. S Afr Rev Sociol. 2017;48(1):42-66.

21. SAS. Local Municipality: Statistics South Africa; 2011. Available from: www.statssa.gov.za/?page_id=993\&id=jozini-municipality.

22. Control Cfd, Prevention. Epi Info, versión 6.04 d. Atlanta: CDC. 2001.
23. Fisher TD, Davis CM, Yarber WL, Davis SL. Handbook of sexualityrelated measures. New York: Routledge; 2013.

24. Seekoe E. Reproductive health needs and the reproductive health behaviour of the youth in Mangaung in the free state province: a feasibility study. Curationis. 2005;28(3):20-30.

25. Bea A. Promoting young father's positive involvement in their children's lives. 2013.

26. Holborn L. Broken families breaking youth. Fast Facts S Afr Inst Race Relat. 2011;5:2-11.

27. Allen AB, Finestone $M$, Eloff I, Sipsma H, Makin J, Triplett $K$, et al. The role of parenting in affecting the behavior and adaptive functioning of young children of HIV-infected mothers in South Africa. AIDS Behav. 2014;18(3):605-16.

28. National adolescent sexual and reproductive health and rights framework strategy (2014-2019). In: Development S, editor. South Africa, Pretoria: Government Publisher; 2015. p. 40.

29. Africa NDoBeS. Integrated school health policy International Journal of Men's Health. 2012.

30. Kea Z. New insights into HIV epidemic in South Africa. 2016.

31. Linganiso WS, Gwegweni JMT. What perpetuate the spread of HIV/ AIDS in rural South African communities? A closer look at social factors. J Public Health Epidemiol. 2016;3(1):1031.

32. Johnson LF, Moolla H, Dorrington RE. Progress towards the 2020 targets for HIV diagnosis and antiretroviral treatment in South Africa. South Afr J HIV Med. 2017;18(1):1-8.

33. Ntombela N, Mashamba-Thompson TP, Mtshali A, Voce A, Kharsany $A B$. The dynamics of HIV transmission in out of school young heterosexual men in South Africa: a systematic scoping review protocol. Syst Rev. 2017;6(1):1-9.

34. Jemmott III JB, Jemmott LS, O'Leary A, Ngwane Z, Icard LD, Heeren $\mathrm{GA}$, et al. Cluster-randomized controlled trial of an HIV/sexually transmitted infection risk-reduction intervention for South African men. Am J Public Health. 2014;104(3):467-73.

35. health POk-Ndo. DISTRICT HEALTH PLAN UMKHANYAKUDE DISTRICT. 2015/2016

36. Coovadia $H$, Jewkes $R$, Barron $P$, Sanders $D$, Mclntyre $D$. The health and health system of South Africa: historical roots of current public health challenges. Lancet. 2009;374(9692):817-34.

37. De Lange N, Geldenhuys M-M. Youth envisioning safe schools: a participatory video approach. S Afr J Educ. 2012;32 (4):494-511.

38. Ditekemena J, Koole O, Engmann C, Matendo R, Tshefu A, Ryder R, et al. Determinants of male involvement in maternal and child health services in sub-Saharan Africa: a review. Reprod Health. 2012;9(1):32.

39. Duff P, Kipp W, Wild TC, Rubaale T, Okech-Ojony J. Barriers to accessing highly active antiretroviral therapy by HIV-positive women attending an antenatal clinic in a regional hospital in western Uganda. J Int AIDS Soc. 2010;13(1):1-10.

40. Pettifor AE, Rees HV, Steffenson A, Hlongwa-Madikizela L, MacPhail C. HIV and sexual behaviour among young South Africans: a nationa survey of 15-24 year olds. Johannesburg. Reproductive Health Research unit. University of Witwatersrand 2004. Accessed from https://pdfs.semanticscholar.org/9497/9bed2096ffff4634e76621d72 da73f793588.pdf on 2 September 2019.

41. HIV/AIDS JUNPo. Global statistics. 2015.

42. Auvert B, Taljaard D, Lagarde E, Sobngwi-Tambekou J, Sitta R, Puren A. Randomized, controlled intervention trial of male circumcision for reduction of HIV infection risk: the ANRS 1265 Trial. PLoS Med. 2005;2 (11):1-12.

43. Patel CJ. Gender role attitudes and attitudes to abortion: Are there gender differences? Social Science Journal. 2009;46:493-505

44. Irinnews. Zulu King revives male circumcision. 2009. http://www. thenewhumanitarian.org/news/2009/12/15/zulu-king-revives-malecircumcision. Accessed 14/08/2019 